\title{
Did we Improve Survival after OHCA in Vienna? Two Trials - Five Years apart
}

\author{
Elisabeth Lobmeyr, Christian Clodi, Michael Poppe, Christoph Schriefl, Fritz Sterz, Alexander Nürnberger \\ Department of Emergency Medicine, Medical University of Vienna, Vienna General Hospital
}

\section{Background}

While out-of-hospital cardiac arrest (OHCA) is still one of the major causes of death in the western world, survivors are rare and outcome is usually poor. To improve this, the European Resuscitation Council (ERC) publishes new guidelines every five years. The purpose of this study was to see, whether we are able to improve survival over the years.

\section{Methods}

Over the last few years two different groups of researchers observed the survival and neurological outcome of victims of OHCA in Vienna. Nürnberger et al. recorded incidence and outcome of the years 2009 and 2010, and another group observed a 24-months period over the years 2013 to 2015 . While in the first time period 1449 patients have been resuscitated by local Emergency Medical Services (EMS), in the second period there have been 2151 interventions. Both studies included patients aged $>18$ years with non-traumatic OHCA with attempted cardiopulmonary resuscitation by a professional EMS crew. As primary endpoints 30-daysurvival and neurological outcome, measured in Cerebral Performance Category (CPC), have been chosen.

\begin{tabular}{|c|c|c|c|}
\hline Parameter & CIRC & QCPR & p-Value \\
\hline Witnessed, n (\%) & $916(55)$ & $1232(57.0)$ & 0.115 \\
\hline Bystander CPR, n (\%) & $689(41)$ & $1204(56)$ & 0.001 \\
\hline \multicolumn{4}{|l|}{ First recorded Rhythm, n (\%) } \\
\hline $\mathrm{VF}, \mathrm{VT}$ & $493(30)$ & $556(26)$ & 0.014 \\
\hline Asystole & $532(32)$ & $832(39)$ & 0.001 \\
\hline PEA & $349(21)$ & $703(33)$ & 0.001 \\
\hline Unknown & $299(18)$ & $58(3)$ & 0.001 \\
\hline $\begin{array}{l}\text { Time to first medical contact, } \\
\text { minutes }\end{array}$ & $10: 29 \pm 5: 45$ & $7: 47 \pm 3: 32$ & 0.001 \\
\hline
\end{tabular}

\section{Results}

From study phase one to study phase two, 30-daysurvival increased from 11.3\% e.g. 17.2\% (181 vs. 372, $\mathrm{p}=0.001)$ and survival with favorable neurological outcome, e.g. CPC 1 or 2 , improved significantly from $8.7 \%$ to $12.6 \%$ (129 vs. $269, p=0.001)$. Bystander resuscitation rose drastically from $41 \%$ to $56 \%$ (689 vs. 1204, $p=0.001$ ) and time to first medical contact decreased significantly from 10:29 $\pm 5: 45$ to $7: 47 \pm$ $3: 32$ minutes, $p=0.001$ ).

\begin{tabular}{llll}
\hline Parameter & CIRC & QCPR/VICAR & p-Wert \\
\hline Sustained ROSC, n (\%) & $385(26)$ & $655(31)$ & 0.006 \\
30-day-survival & $181(11)$ & $372(17)$ & 0.001 \\
CPC1/2, n (\%) & $129(8)$ & $269(13)$ & 0.001 \\
\hline
\end{tabular}

\section{Conclusion}

While immigration, a higher level of public awareness and various preclinical first responder programs could play a big part in the increasing number of out-ofhospital cardio-pulmonary resuscitations, changes in the ERC guidelines in the year 2010, with focus on layhelper resuscitation, early defibrillation and minimized hands-off-times are probably responsible for a significantly better survival in quantity and quality in Vienna.

\section{References}

Hubner, P. et al. (2017) 'Improvements in the quality of advanced life support and patient outcome after implementation of a standardized real-life post-resuscitation feedback system', Resuscitation, 120, pp. 38-44. doi: $10.1016 /$ j.resuscitation.2017.08.235

Nolan, J. P. et al. (2010) 'European Resuscitation Council Guidelines for Resuscitation 2010 Section 1. Executive summary', Resuscitation, 81(10), pp. 12191276. doi: 10.1016/j.resuscitation.2010.08.021.

Nürnberger, A. et al. (2013) 'Out of hospital cardiac arrest in Vienna: Incidence and outcome', Resuscitation, 84, pp. 42-47. doi: 10.1016/j.resuscitation.2012.07.002. 